\title{
Adhesion molecules in experimental peanut allergy
}

\author{
Jami Bennett ${ }^{1}$, Steven Maltby ${ }^{1}$, Erin Frohwerk ${ }^{1}$, Kay Jian ${ }^{1}$, Helen Merkens ${ }^{1}$, Mathew Tunis ${ }^{2}$, Kelly McNagny $^{1 *}$ \\ From AllerGen NCE Inc.'s Fifth Annual Research Conference: Innovation from Cell to Society \\ Québec City, QC, Canada. 7-9 February 2010
}

\section{Objective/purpose}

Adhesion molecules are critical for appropriate localization of leukocytes and induction of adaptive immune responses throughout the body. Our aim is to better understand the role of cell trafficking and adhesion molecules in an experimental model of peanut allergy.

\section{Methods}

Peanut allergy was induced in mice on the $\mathrm{C} 57 \mathrm{Bl} / 6$ background $\left(\mathrm{IA}^{\mathrm{b}}\right)$ with 4 weekly oral gavage feedings of peanut protein and cholera toxin. After a two-week rest period, sensitized animals were challenged by intraperitoneal injection with crude peanut extract (CPE) and monitored for anaphylaxis. Clinical indicators of peanut allergy include decreased body temperature, scratching, swollen eyes, decreased movement and responsiveness, and moribund condition. We evaluated plasma histamine, total IgE, peanut-specific IgE, and peritoneal albumin levels as in vivo indicators of mast cell degranulation and vascular permeability.

Targeted genes and phenotypes

\section{$\mathrm{CD}^{-1-}$}

Normally a surface marker of hematopoietic stem cells, mast cells, eosinophils and DCs, required for efficient cell migration. Mice exhibit attenuation of most mucosal inflammatory disease models.

\section{$\mathrm{CD}_{103^{-1-}}$}

Alpha-chain of integrin expressed by mucosal DCs and $\mathrm{T}$ cells which facilitates binding to mucosal epithelial cells; Mice exhibit exacerbated Th2 inflammatory responses.

\footnotetext{
* Correspondence: Kelly@brc.ubc.ca

${ }^{1}$ Biomedical Research Centre, University of British Columbia, Vancouver, British Columbia, Canada

Full list of author information is available at the end of the article
}

IL7-Ra'-1-

Required for $\mathrm{T}$ cell homing and efficient $\mathrm{T}$ and $\mathrm{B}$ cell development. Mice exhibit impaired adaptive immune responses.

\section{L-Selectin ${ }^{-/-}$}

Adhesion molecule required for appropriate localization of naïve lymphocytes to primary lymphoid tissue. Mice exhibit impaired primary adaptive immune responses.

\section{PSGL-1/- and E-Selectin ${ }^{-/-}$}

Adhesion molecules required for efficient homing of inflammatory cells to the sites of inflammation. Mice exhibit attenuated inflammatory responses.

\section{Findings}

CD34, CD103, PSGL-1, E-Selectin, and probably PSelectin are likely dispensible for induction of experimental peanut allergies since deficient animals are fully susceptible to peanut induced anaphylaxis. This likely reflects the fact that, although each of these mice exhibit a delay in the induction of inflammatory disease, none exhibit a complete block in inflammatory homing. Since our evaluation of acute allergic reactions occurs after several priming steps it is likely that these mice exhibit sufficient inflammatory homing to render them susceptible to an acute challenge. In stark contrast, adhesion molecules required for the appropriate localization of lymphocytes prior to sensitization (L-Selectin) and those required for efficient formation of adaptive immune cells (IL7-Ra) are required for induction of peanut induced anaphylaxis since mice lacking these molecules exhibited a strong protection from anaphylaxis.

\section{Deliverables}

Our data suggest that, with the exception of L-Selectin, most of the molecules known to play a role in leukocyte 
homing do not play a major role in acute allergeninduced anaphylaxis and would, therefore, be poor targets for therapy. Future studies will focus on how LSelectin inactivation leads to amelioration of peanut allergies. We will test relevant methods of interfering with this site-specific function and attempt to block antigen transit/priming without breaking oral tolerance to other antigens routinely encountered in the gut.

\section{Relevance}

Food allergy and peanut allergy in particular, is a major health challenge for many young people in Canada. Understanding the role of immune cell function and localization is critical to our ability to modulate mucosal inflammation and disease. Our findings will inform future efforts to generate therapies for food allergic patients and identify or eliminate potential therapeutic targets for food allergy, ultimately enhancing the therapeutic options and quality of life for affected patients. These data will be published in peer-reviewed journals, presented in abstracts and seminars, and reported as part of the CanGoFAR project summary to deliver the findings to the community and relevant policy makers.

\section{Acknowledgements}

Research funded by CanGoFAR/Hematopoietic Stem Cell Markers in Diagnosis \& Prediction of Allergic Inflammation \& Disease; Postdoctoral Fellowship, Multiple Sclerosis Society of Canada (JLB), Postgraduate Scholarship-Doctoral, Natural Sciences and EngineeringResearch Council (EJF); Strategic Training Program in Transfusion Science, CIHR/HSFC through CBR (SM), Research Scholar, Michael Smith Foundation for Health Research (KMM), and operating funds from CIHR (Canadian Institutes of Health Research)

\section{Author details}

'Biomedical Research Centre, University of British Columbia, Vancouver, British Columbia, Canada. ${ }^{2}$ Department of Microbiology \& Immunology, Dalhousie University, Halifax, Nova Scotia, Canada.

Published: 26 November 2010

doi:10.1186/1710-1492-6-S3-P10

Cite this article as: Bennett et al:: Adhesion molecules in experimental peanut allergy. Allergy, Asthma \& Clinical Immunology 2010 6(Suppl 3):P10.
Submit your next manuscript to BioMed Central and take full advantage of:

- Convenient online submission

- Thorough peer review

- No space constraints or color figure charges

- Immediate publication on acceptance

- Inclusion in PubMed, CAS, Scopus and Google Scholar

- Research which is freely available for redistribution

Submit your manuscript at www.biomedcentral.com/submit 